\title{
NUTRITION STATUS IN COMMUNITY DWELLING OLDER POPULATION IN AN EGYPTIAN URBAN AREA
}

\author{
H.M.M. Abdelrahman ${ }^{1}$, A.E.E. Elawam ${ }^{1}$
}

\begin{abstract}
Objectives: To evaluate the nutrition status in community dwelling Egyptian older subjects, living in Cairo, and the factors that may be associated with malnutrition. Design: A cross-sectional study. Setting: Egyptian social clubs, in Cairo. Participants: 318 older subjects, 60 years old and above. Measurements: Comprehensive Geriatric Assessment and Mini Nutritional Assessment. Results: The nutrition status of the sample was: $44 \%$ (140 subjects) were well nourished, $41.5 \%$ (132 subjects) had risk of malnutrition and $14.5 \%$ (46 subjects) were malnourished. the mean age of the well-nourished patients was $64 \pm 3.16$, while for malnourished patients was $72.3 \pm 4.83[\mathrm{P}:<0.001]$. Sex did not show a significant difference between well-nourished and malnourished patients [P: 0.35]. Also marital status did not show significant affection of nutritional status [P: 0.254]. While education level and employment status showed significant difference between well-nourished and malnourished patients [P: $<0.001]$. The functional state assessed by ADL showed a significant difference between well-nourished and malnourished patients [P: <0.007]. Also the Cognitive impairment was more among malnourished than well-nourished patients [P: 0. $<0.001]$. Depression and polypharmacy were significantly found more among malnourished than well-nourished patients [P: 0.009, 0. 001] respectively. logistic regression analysis revealed that increased age, low score of MMSE, less years of education and increased number of medications were independent risk factor for malnutrition. Conclusion: Malnutrition and risk of malnutrition were prevalent in community dwelling older population, especially with increased age, less education, living alone, unemployment, cognitive impairment, depression and taking multiple medications. So we recommend that nutritional assessment to be included in any assessment of elderly person.
\end{abstract}

Key words: Community dwelling, older population, malnutrition.

\section{Background}

Malnutrition is defined as an imbalance of nutrients caused by either an excess intake of nutrients or a nutritional deficit. Malnutrition is becoming increasingly more common among the elderly population. This is a cause for concern considering malnutrition negatively affects the health of the older adult. An estimated 5-10\% of elderly people living in the community setting are malnourished (1).

Malnutrition is highly prevalent in the elderly population (2). It has been reported in other places that $15 \%$ of community-dwelling and home-bound elderly individuals, up to $62 \%$ of hospitalized elderly patients, and up to $85 \%$ residents of nursing homes are malnourished (3). It increases morbidity, mortality and decreases quality of life (4).

1. Ain Shams University, Faculty of Medicine, Geriatric Department, Cairo, Egypt

Corresponding Author: Dr. Hossameldin Mohamed Mohamed Abdelrahman, MD Geriatric Medicine, Lecturer of Geriatric Medicine, Faculty of Medicine, Ain Shams University, Cairo, Egypt. Email: hossamabdelrahman@hotmail.com
About $60 \%$ of hospitalized older adults (age 65 or older) and 35-85\% in long-term care facilities are experiencing malnutrition (1). From these statistics, malnutrition seems to be even more prevalent in hospitals and long-term care facilities, as compared to community-dwelling older adults. In the United States, the elderly population is expected to double and reach approximately 72 million people by 2030 (5). Addressing the more complex needs of the older adult, including nutritional needs, malnutrition represents an important public health issue given the changing demographics.

Consideration of nutritional status and risk of malnutrition have been particularly recommended for older adults. Good nutritional status is essential to promote good health and prevent disease in older adults (6).

Follow-up studies have found an increased prevalence of adverse health outcomes (e.g. increased morbidity, mortality and discharge to nursing home) among old people classified as malnourished or at risk of malnutrition at baseline, when compared to those classified as well nourished. Hence, old people who 
obtain a low amount of Mini Nutritional Assessment (MNA) points might not only be at risk of malnutrition, but also at risk of more serious outcomes in the future. These associations have been used to state an apparent predictive validity of MNA (7).

Nutritional well-being is a fundamental component of the health, independence and quality of life in older individuals (8). Protein-energy under-nutrition, can lead to undesirable health risks, including loss of independence (9), longer length of hospital stay, poorer function and quality of life, readmission to hospital, discharge to higher level care (10) and increased risk of fragility fractures and mortality (11), as well as delayed wound healing and slower recovery from surgery (12).

The presence of malnutrition is found to be associated with delayed wound healing (13), impaired immune function, poor muscle function (14), mental health problems (15), impaired quality of life (16) and even increased morbidity and mortality rates (17).

Even when older adults are living independently; changes in appetite, limited mobility, social isolation and economic constraints, often combined with the presence of chronic diseases and use of many medications, can all adversely affect nutritional status (18). Hence the need to identify those at risk of malnutrition is critical in providing optimal care and promoting good nutritional status in community-dwelling older adults (19).

Malnutrition may be secondary to certain conditions (disease-related malnutrition), such as cancer, arthritis, diabetes, or emphysema. It is also a condition in its own right. Common risk factors for malnutrition are summarized below (20).

\section{Risk factors for malnutrition in older people (21)}

Clinical factors:

- Poor appetite

- Poor dentition

- Loss of taste and smell

- Disability and limited mobility

- Drug interactions

- Other disease states (cancer, diabetes, arthritis...)

Lifestyle and social factors:

- Lack of knowledge about food, cooking and nutrition

- Isolation and loneliness

- Poverty

- Inability to shop or prepare food

Psychological factors:

- Confusion

- Depression

- Anxiety

- Bereavement

- Dementia
- Socioeconomic status remains an important predictor of nutritional status.

Dwindling savings and decreased earning capacity put older people at increased risk of malnutrition. Polypharmacy is common in older people, especially with the increased likelihood of multiple, chronic medical ailments. Poor health and an increasing number of medical illnesses are also associated with impaired nutritional status (22). Mood and cognition are vital determinants of an older person's overall wellbeing. Social isolation not only leads to decreased nutrient intake but can also lead to depression (23). Depression is an independent predictor of nutritional risk and perhaps antidepressant therapy may promote weight gain or prevent weight loss in elderly people. Dementia is more prevalent with increasing age and significant weight loss is frequently seen $(24,25)$.

With regard to prevention, screening can be a part of the high-risk or individual based approaches, where one seeks to identify individuals who are liable to develop disease and disability in the future, and then help them to obtain protection or to take avoiding action (26).

The frequent failure to recognize and treat malnutrition, especially where it is common, is unacceptable. In such circumstances the routine use of simple screening tools to identify high-risk individuals is recommended (27).

\section{Subjects and Methods}

\section{Study setting and sample}

- A cross-sectional study was conducted to evaluate the nutrition status of community dwelling Egyptian older subjects, living in Cairo, and the factors that might be associated with malnutrition.

- 318 older subjects 60 years old were randomly selected from four Egyptian social clubs in Cairo, over 3 months from January to March, 2010.

\section{Data collection}

All subjects were subjected to:

1. Informed oral consent.

2. Comprehensive geriatric assessment including:

- Age, gender, marital status, employment, living arrangement, education, poly pharmacy.

- Assessment of functional state using ADL: (28)

The subject was considered assisted if more than one daily activity is assisted and dependent if the subject was dependent in all the activities of daily living.

- Screen for depression using GDS 15: (29) 
Geriatric Depression Scale 15 items: It is used for screening of depression; patients who score more than 5 positive items were considered to be depressed. It had been translated into Arabic slang language suitable for illiterate subjects concerning the meaning of each depressive item included, and validated for detection of cases of depression, because its results significantly correlate with the results of Beck Depression Inventory (B.D.I.)

- Assessment of cognitive functions using MMSE: (30)

All subjects were screened for cognitive functions by using the Arabic version of MMSE (31).

The MMSE was selected because it is the best studied instrument for screening for dementia (32).

The MMSE comprises 30 questions with 10 devoted to orientation (five regarding time and five regarding place). Three items requiring registration of new information (repeating three words). Five questions addressing attention and calculation. Mental control questions requiring patient to make five serial subtractions of 7 from 100 or spell word backward). Three recall items (remembering the three registration items). eight items assessing language skills (two naming items, repeating phrase, following a three-step command, reading and following a written command and writing a sentence), and one construction question (copying a figure consisting of two overlapping pentagons) (30).

\section{The Mini Nutritional Assessment (MNA)}

A method has been designed to provide a screening of nutritional risk in old people in order to facilitate nutritional support (33). It helps the healthcare professionals (physicians, nurses, dieticians' etc.) to assess the nutritional status of the elderly and guides them towards intervention. The MNA is composed of four parts: (I) anthropometrical measurements; (II) global assessments; (III) dietary questionnaire; and (IV) subjective assessment. The total obtainable score is 30 points. If an old person scores $<17$ points he is classified as malnourished. If he scores 17 to 23.5 points he is at risk of malnutrition. Finally, if he obtains $>23.5$ points he is classified as well nourished.

\section{Statistical Methods}

All data were entered into the 21th version of SPSS (Statistical Package of Social Science) and analyzed using frequency and descriptive statistics to analyze the study population. Frequency and percentage was calculated for all qualitative data; data with a limited number of distinct values or categories (for example, gender or religion). Description of all data in the form of mean (M) and standard deviation (SD) was done for all quantitative data; data measured on an interval or ratio scale, where the data values indicate both the order of values and the distance between values.

Comparison of qualitative variables was done using Chi-square test; it is a test that determines the extent that a single observed series of proportions differs from a theoretical or expected distribution of proportions, or the extent that two or more series of proportions or frequencies differ from one another based on the chisquare distribution.

Comparison between quantitative variables was done using t-test to compare two groups, and ANOVA (analysis of variance) to compare more than two groups.

The level of significance for Chi-square test, t-test and ANOVA was taken at $P$ value $<0.05$ is significant, otherwise is non significant.

Logistic regression analysis was performed using the conditional forward elimination procedure. The entry criterion for the multivariate model was $P_{-} .05$.

\section{Results}

The study was conducted on 318 older patients, Table 1 showed the demographics and characteristics of the older adults: The mean age of the sample was $66.7 \pm 4.8$ (range: $60-82)$. The sample included $149(46.9 \%)$ males and $169(53.1 \%)$ females. Among the 318 older subjects; $158(49.7 \%)$ were married, $128(40.3 \%)$ were widowed, 23 $(7.2 \%)$ were divorced and $9(2.8 \%)$ were single. Regarding education; $36(11.3 \%)$ were illiterate, $96(30.2 \%)$ received less than high school education and $186(58 \%)$ received high school education or more. Regarding work; 119 $(37.4 \%)$ were employed and $199(62.6 \%)$ were unemployed. Regarding living arrangement; 163 (51.3\%) were living with family members, $51(16 \%)$ were living alone and $104(32.7 \%)$ were living with non family members. Regarding cognitive functions; 145 (45.6\%) had normal cognitive function, 127 (39.9\%) had mild cognitive impairment $46(14.5 \%)$ had dementia. Regarding depression; $180(56.6 \%)$ were not depressed and 138 $(48.3 \%)$ were depressed. Regarding functional status; 95 (29.9\%) were independent, $156(49.1 \%)$ were assisted and $67(21.1 \%)$ were dependent.

Table 2 showed the association between patients' demographics and characteristics with malnutrition; the mean age of the well-nourished patients was $64 \pm 3.16$, while for malnourished patients was $72.3 \pm 4.83$ [P: $<0.001]$. Sex did not show a significant difference between well-nourished and malnourished patients [P: 0.35]. Also marital status did not show a significant affection of nutritional status as [P: 0.254]. While education level and employment showed significant differences between well-nourished and malnourished patients [P: $<0.001]$. The functional status, assessed by ADL, showed a significant difference between well-nourished and malnourished patients [P: $<0.007]$. Also the Cognitive impairment was more among malnourished than well- 
nourished patients [P: $0 .<0.001]$. Depression and polypharmacy were significantly found in malnourished than well-nourished patients [P: 0.009, 0. 001 respectively].

Table 1

The sample's demographic characteristics

\begin{tabular}{|c|c|}
\hline \multicolumn{2}{|l|}{$\overline{\text { Age }}$} \\
\hline Min & 60 \\
\hline Max & 82 \\
\hline Mean \& SD & $66.7 \pm 4.8$ \\
\hline \multicolumn{2}{|l|}{ Sex } \\
\hline Male & $149(46.9 \%)$ \\
\hline Female & $169(53.1 \%)$ \\
\hline \multicolumn{2}{|l|}{ Marital status: } \\
\hline Married & $158(49.7 \%)$ \\
\hline Widow & $128(40.3 \%)$ \\
\hline Divorced & $23(7.2 \%)$ \\
\hline Single & $9(2.8 \%)$ \\
\hline \multicolumn{2}{|l|}{ Education: } \\
\hline Illiterate & $36(11.3 \%)$ \\
\hline Less than High school education & $96(30.2 \%)$ \\
\hline High school education and more & $186(58 \%)$ \\
\hline \multicolumn{2}{|l|}{ Occupation : } \\
\hline Employed & $119(37.4 \%)$ \\
\hline Unemployed & $199(62.6 \%)$ \\
\hline \multicolumn{2}{|l|}{ Living arrangement : } \\
\hline Living with family members & $163(51.3 \%)$ \\
\hline Living alone & $51(16 \%)$ \\
\hline Living non family members & $104(32.7 \%)$ \\
\hline \multicolumn{2}{|l|}{ MMSE: } \\
\hline Normal & $145(45.6 \%)$ \\
\hline Mild cognitive impairment & $127(39.9 \%)$ \\
\hline Dementia & $46(14.5 \%)$ \\
\hline \multicolumn{2}{|l|}{ GDS: } \\
\hline Not depressed & $180(56.6 \%)$ \\
\hline Depressed & $138(48.3 \%)$ \\
\hline \multicolumn{2}{|l|}{ ADL } \\
\hline Independent & $95(29.9 \%)$ \\
\hline Assissted & $156(49.1 \%)$ \\
\hline Dependent & $67(21.1 \%)$ \\
\hline
\end{tabular}

Table 3 confirmed by logistic regression analysis that increased age, low score of MMSE, less years of education and increased number of medications were independent risk factor for malnutrition $[\mathrm{P}:<0.001,0.034,0.012,0.033$ respectively].

\section{Discussion}

In our study we found that the prevalence of malnutrition in community dwelling Egyptian older adult was $14.5 \%$ and the prevalence of those at risk of malnutrition was $41.5 \%$. We found also that these percentages significantly increased in those who were older, less educated, living alone, unemployed, cognitively impaired, depressed and using multiple drugs. Moreover, our results revealed increased age, low score of MMSE, less years of education and increased number of medications were independent risk factor for malnutrition.

\section{Figure 1}

The nutrition status of the sample was: $44 \%$ (140 subjects) were well nourished, $41.5 \%$ (132 subjects) had risk of malnutrition and $14.5 \%$ (46 subjects) were malnourished

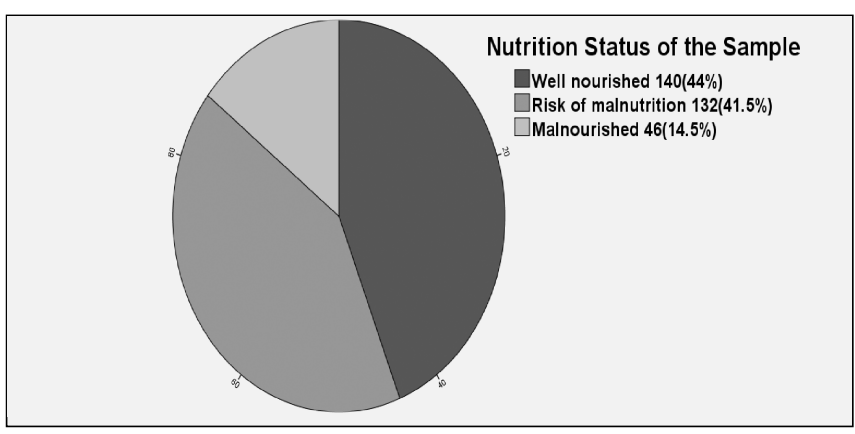

Our results were supported by Van Wayenburg et al., 2005, (34) and Wijnhoven et al., 2012 (35) who conducted studies to determine the prevalence of under nutrition in community-dwelling older individuals and they found that the prevalence ranged from 0 to $24 \%$.

Supporting our findings, Hajjar et al. 2004 (36) reported that the prevalence of malnutrition was $15 \%$ of older adults living in the community.

Also we agreed with Janneke Schilp et al., 2012 (37) who found that the prevalence of under nutrition in Dutch community-dwelling older individuals (> $65 \mathrm{y}$ ) was $11 \%$ in a representative sample, and also they reported increasing prevalence of under nutrition with age.

The same findings were supported by Rist et al., 2012 (38) who conducted an Australian study on communityliving older adults receiving home nursing services, they reported that $8 \%$ of clients were malnourished according to the Mini Nutritional Assessment with a further 35\% of clients were identified as being at risk of malnutrition

Also Watterson et al., 2009 (39) reported that malnutrition prevalence in the community had been to vary from $10-30 \%$.

Other studies reported different prevalence percentages; Visvanathan et al., 2003 (40) conducted a study of 250 clients of a home care service, they found that over a third of clients at-risk of malnutrition but only $4 \%$ were classified as malnourished. And this could be explained as these clients were receiving home care services that usually provided high level of care services, so the meals provided would be expected to be efficient.

Regarding the association between malnutrition and other patients' characteristics, our study revealed a significant association between malnutrition and age, education, living alone, unemployment, cognitive impairment, depression and polypharmacy. 
Table 2

The relationship between the sample's demographic characteristics and nutrition status

\begin{tabular}{|c|c|c|c|c|c|c|c|c|}
\hline \multirow{3}{*}{ Age } & \multicolumn{2}{|c|}{ Well nourished } & \multicolumn{2}{|c|}{ Risk of malnutrition } & \multicolumn{2}{|c|}{ Malnourished } & \multirow[b]{2}{*}{$\mathrm{F}$} & \multirow{3}{*}{$\begin{array}{l}82.7 \\
<0.001\end{array}$} \\
\hline & Mean & $\mathrm{SD}$ & Mean & SD & Mean & SD & & \\
\hline \multirow{2}{*}{\multicolumn{9}{|c|}{ Sex }} \\
\hline & & & & & & & & \\
\hline Male & 72 & & 57 & & 20 & & $\mathrm{X}$ & 2.1 \\
\hline Female & 68 & & 75 & & 26 & & $\mathrm{P}$ & 0.35 \\
\hline \multicolumn{9}{|l|}{ Marital status: } \\
\hline Married & 68 & & 70 & & 20 & & $X$ & 7.78 \\
\hline Widow & 56 & & 49 & & 23 & & $\mathrm{P}$ & 0.254 \\
\hline Divorced & 10 & & 12 & & 1 & & & \\
\hline Single & 6 & & 1 & & 2 & & & \\
\hline \multicolumn{9}{|l|}{ Education: } \\
\hline Illiterate & 4 & & 20 & & 12 & & $X$ & 44.7 \\
\hline Less than High school education & 29 & & 46 & & 21 & & $\mathrm{P}$ & $<0.001$ \\
\hline High school education and more & 107 & & 66 & & 13 & & & \\
\hline \multicolumn{9}{|l|}{ Occupation: } \\
\hline Employed & 82 & & 34 & & 3 & & $\mathrm{X}$ & 53.16 \\
\hline Unemployed & 58 & & 98 & & 43 & & $\mathrm{P}$ & $<0.001$ \\
\hline \multicolumn{9}{|l|}{ Living arrangement: } \\
\hline Living with family members & 88 & & 74 & & 1 & & $x$ & 54.7 \\
\hline Living alone & 14 & & 20 & & 17 & & $\mathrm{P}$ & $<0.001$ \\
\hline Living non family members & 38 & & 38 & & 28 & & & \\
\hline \multicolumn{9}{|l|}{ MMSE: } \\
\hline Normal & 90 & & 46 & & 9 & & $\mathrm{X}$ & 75.04 \\
\hline Mild cognitive impairment & 40 & & 72 & & 15 & & $\mathrm{P}$ & $<0.001$ \\
\hline Dementia & 10 & & 14 & & 22 & & & \\
\hline \multicolumn{9}{|l|}{ GDS: } \\
\hline Not depressed & 92 & & 68 & & 20 & & $X$ & 9.33 \\
\hline Depressed & 48 & & 64 & & 26 & & $\mathrm{P}$ & 0.009 \\
\hline \multicolumn{9}{|l|}{ ADL: } \\
\hline Independent & 47 & & 42 & & 6 & & $X$ & 13.99 \\
\hline Assisted & 66 & & 68 & & 22 & & $\mathrm{P}$ & 0.007 \\
\hline Dependent & 27 & & 22 & & 18 & & & \\
\hline \multirow{2}{*}{ Polypharmacy: } & Mean & SD & Mean & SD & Mean & SD & $\mathrm{F}$ & 14.46 \\
\hline & 2.08 & 1.04 & 2.08 & 1.004 & 1.47 & 0.54 & $\mathrm{P}$ & 0.001 \\
\hline
\end{tabular}

Table 3

Logistic regression analysis of the risk factors associated with malnutrition

\begin{tabular}{llll}
\hline Variables & Relative risk & CI & PValue \\
\hline Age & & & \\
MMSE & 0.658 & $0.584-0.740$ & $<0.001$ \\
Years of education & 0.167 & $1.012-1.346$ & 0.034 \\
Polypharmacy & 0.454 & $0.059-0.701$ & 0.012 \\
\hline
\end{tabular}

As for age, we agree with Baweja et al., 2008 (41) and Soini et al., 2004 (42) who reported that as the age increased, malnutrition and risk of malnutrition increased.

Also Sarah et al., 2005 (43) conducted a cross-sectional study with the aim to measure the effect, if any of age, on nutritional status in elderly people. After adjusting for disability and co-mobility, they found that age alone had had a significant and independent effect on important anthropometric and biochemical nutritional assessment variables. They concluded that increasing age was independently associated with poor nutritional status.

This can be explained as with aging the older adult becomes more dependent, less mobile and will suffer from different types of diseases like hypertension, diabetes Mellitus, ischemic heart disease, acid peptic disease, dementia, dental problems and difficulties in intake of diet, also social isolation further aggravates the problem.

Regarding the association between sex and malnutrition, our study did not reveal any significant difference between males and females. This was supported by Georgie et al., 2012, (44) who reported that malnutrition risk showed no significant differences for age, gender, country of birth or living arrangements.

This could be explained by the fact that aging changes affecting elderly people are the same for both males and females and their effect on malnutrition will be the same for both sexes.

Regarding the association between malnutrition and depression, we agreed with Winter et al., 2013 (45) and Cabrera et al., 2007 (46) and Kvamme et al., 2011 (47) who 
found that those at risk of malnutrition were twice as likely to have a history of depression.

Also Donini et al., 2003 (48) supported this finding as they reported that psychological and socio-economic problems such as depression, life events and loneliness may reduce appetite. They added that loneliness and reluctance to eat may complicate an already marginal situation for nutritional risk in the elderly.

Regarding living arrangement we found no significant relationship between living alone and nutritional status, while Walker et al., 1991 (49) reported that loneliness, especially when combined with recent bereavement or poor social support, had been shown to be a common and significant risk factor for malnutrition.

This can be explained as living alone is usually associated with anorexia and loss of motivation to prepare and eat food. While our results could be explained as the patents living alone represented only $25.5 \%$ and also the patients living with non family represented only $18.6 \%$.

We found a significant association between the level of education and malnutrition. This was supported by Maliheh et al., 2008 (50) who conducted a study and revealed that nutritional status had been associated with education, and a higher level of education had been possibly associated with higher income and better lifestyle, which in turn had resulted in a better nutritional status in those elderly.

Regarding medications, we found a significant association between polypharmacy and malnutrition; many studies supported this finding, e.g. Saka et al., 2010 (51) reported that with age, the risk of developing various diseases and conditions increased, and diseases such as dementia, depression, and the presence of infections are often associated with malnutrition. They added that drug therapy could negatively affect nutritional status through the side effects often caused by polypharmacy such as decreased appetite, nausea, alterations in taste and smell, dry mouth, constipation, diarrhea, and confusion.

So added to their explanation, polypharmacy usually has negative effect on the nutritional status due to the fact that elderly people often have higher prevalence of diseases leading to lower food intake due to pain, nausea, confusion, immobility and drug side-effects. The reasons for the poor food in-take in the elderly are likely to be linked to both physiological and pathological factors.

Regarding functional impairment, we found that it was significantly associated with malnutrition, and this was mentioned in many studies reported that immobility and physical impairment were significantly related to poor food intake and anorexia and eventually malnutrition.

Regarding cognitive impairment, our study revealed also that it was significantly associated with malnutrition. A study was conducted by Lee et al., 2000 (52) on 282 institutionalised elderly subjects living in Hong Kong, they found that the risk of malnutrition in those suffering from dementia was 10 times higher than in those who were not demented.

Another study conducted by Pearson et al., 2001 (53) on 627 elderly subjects who lived in European small towns showed that those with possible cognitive impairment were more than twice likely to be malnourished. And this can be explained as cognitive impairment and dementia often affect motivation and planning abilities.

\section{Conclusion}

Malnutrition and risk of malnutrition are prevalent in community dwelling older adult especially with increase age, less education, living alone, unemployment, cognitive impairment, depression and using multiple drugs. So we recommend nutritional assessment to be included in any assessment of older adult.

Conflicts of interest: The authors declare that there are no conflicts of interest.

Ethical standards: The research project has been approved by administrative offices of the social clubs within which the work was undertaken. A verbal consent was taken from all participants before their enrollment in the study.

\section{References}

1. Furman, E.F. Undernutrition in Older Adults Across the Continuum of Care. Journal of Gerontological Nursing, 2006;1(32): 22 - 27.

2. Kushner R, Ayello E, Beyer P, Skipper A, Van Way C, Young E., Balogun L. National Coordinating Committee: clinical indicators of nutrition care. J Am Diet Assoc. 1994;94:1168-77.

3. Kagansky N, Berner Y, Koren-Morag N, Perelman L, Knobler H, Levy S. Poor nutritional habits are predictors of poor outcome in very old hospitalized patients. Am J Clin Nutr. 2005;82:784-91

4. Thomas DR, Zdrowski CD, Wilson MM, Conright KC, Lewis C, Tariq S, Morley JE. Malnutrition in subacute care. Am J Clin Nutr. 2002;75:308 -13.

5. Shahin ES, Meijers JM, Schols JM, Tannen A, Halfens RJ, Dassen T. The relationship between malnutrition parameters and pressure ulcers in hospitals and nursing homes. Nutrition, 2010;26:886-9.

6. Green SM, Watson R. Nutritional screening and assessment tools for older adults: literature review. J Adv Nurs, 2006;54: 477 - 90.

7. Guigoz Y, Lauque S, Vellas BJ. Identifying the elderly at risk for malnutrition. The Mini Nutritional Assessment. Clin Geriatr Med, 2002;18:737 - 57.

8. DiMaria-Ghalili RA, Amella E. Nutrition in older adults. Am J Nurs, 2005;105(3):40-50.

9. Macintosh C, Morley J, Chapman I. The anorexia of aging. Nutrition, 2000;16:983-5.

10. Visvanathan R, Newbury J, Chapman I. Malnutrition in older people: screening and management strategies. Aust Fam Physician, 2004;33:799- 805.

11. Neumann S, Miller M, Daniels L, Crotty M. Nutritional status and clinical outcomes of older patients in rehabilitation. J Hum Nutr Diet. 2005;18:129- 36.

12. Miller M, Thomas J, Cameron I, Chen J, Sambrook P, March L, Cumming R et al. Body mass index: a simple, rapid and clinically meaningful index of under-nutrition in the oldest-old? Brit J Nutr, 2008;101:1300-5.

13. Kawakami K, Kadota J, Iida K, Shirai R, Abe K, Kohno S. Reduced immune function and malnutrition in the elderly. Tohoku J ExpMed, 1999;187:157-71.

14. Bourdel-Marchasson I, Joseph PA, Dehail P, Biran M, Faux P, Rainfray M, et al. Functional and metabolic early changes in calf muscle occurring during nutritional repletion in malnourished elderly patients. Am J Clin Nutr, 2001;73:832-8.

15. Kvamme JM, Gronli O, Florholmen J, Jacobsen BK. Risk of malnutrition is associated with mental health symptoms in community living elderly men and women: the Tromso study. BMC Psychiatry, 2011;11:112.

16. Amarantos E, Martinez A, Dwyer J. Nutrition and quality of life in older adults. J Gerontol A Biol Sci Med Sci, 2001;56:54-64.

17. Ferreira LS, do Amaral TF, de Fatima Nunes Marucci M, Costa Nascimento LF, Lebrao ML, de Oliveira Duarte YA. Undernutrition as a major risk factor for death among older Brazilian adults in the community dwelling setting: SABE survey. Nutrition, 2011;27:1017-22. 
18. Sharkey J, Branch L, Zohoori N, Giuliani C, Busby- Whitehead J, Haines P. Inadequate nutrient intakes among homebound elderly and their correlation. Am J Clin Nutr. 2002;76:1435-45.

19. Brownie S. Why are elderly individuals at risk of nutritional deficiency? Int J Nurs Pract. 2006;12:110-8.

20. Pirlich $\mathrm{M}$ et al. "Prevalence of Malnutrition in Hospitalized Medical Patients: Impact of Underlying Disease" Digestive Diseases, 2003;21: 245-251.

21. Hickson M. Malnutrition and ageing. Postgrad Med J, 2006; 82: 2-8.

22. Nelson K, Brown ME, Lurie N. Hunger in an adult patient population. JAMA, 1998;279:1211-1214.

23. Guarnieri G, Antonione R, Biolo G. Mechanisms of malnutrition in uraemia. J Ren Nutr, 2003;13:153-157.

24. Brodaty H, Luscombe G, Parker G, et al. Increased rate of psychosis and psychomotor change in depression with age. Psychol Med, 1997;27:1205-1213.

25. Wolf-Klein GP, Silverstone FA, Levy AP. Nutritional patterns and weight change in Alzheimer patients. Int Psychogeriatr, 1992;4:103-118.

26. Rose G. High-risk and population strategies to prevention: ethical considerations. Ann Med, 1989;21:409 - 13.

27. Elia M, Zellipour L, Stratton RJ. To screen or not to screen for adult malnutrition? Clin Nutr, 2005;24:867 - 84 .

28. Katz s, Ford A, Moskowitz R, et al. The index of Activities of Daily Living Standardized measure of biological and psychological function. J. AMA, 1963;185: $914-919$.

29. Beck AT, Ward $\mathrm{CH}$, Mendelson $\mathrm{M}$, et al. An inventory for measuring depression. Arch. Of General Psychiat. 1961;4: 561.

30. Folstein MF, Folstein SE, McHugh PR. "Mini-mental state". A practica method for grading the cognitive state of patients for the clinician. Journal of psychiatric research, 1975;12:189-198.

31. El-Okl MA, El Banouby MH , El Etrebi A. Prevalence of Alzheimer dementia and other causes of dementia in Egyptian elderly. MD Thesis, 2002; Faculty of Medicine, Ain Shams University, 2002.

32. United States Preventive Services Task Force. Screening for Dementia: Recommendation and Rationale. Ann Intern Med. 2003; 138(11):925-926.

33. Guigoz Y, Vellas B, Garry PJ. Mini Nutritional Assessment: a practical assessment tool for grading the nutritional state of elderly patients. Facts and Research in Gerontology, 1994;2:15-59.

34. Van Wayenburg CA, Van de Laar FA, Van Weel C, Van Staveren WA, Van Binsbergen JJ. Nutritional deficiency in general practice: a systematic review. Eur J Clin Nutr, 2005;59: 81-7.

35. Wijnhoven HA, Schilp J, Van Bokhorst-de van der Schueren MA, De Vet HC, Kruizenga HM, Deeg DJH, et al. Development and validation of criteria for determining undernutrition in community-dwelling older men and women the Short Nutritional Assessment Questionnaire 65p. Clin Nutr, 2012;31:351-8.

36. Hajjar R et al. "Malnutrition In Aging" Internet Journal of Geriatrics and Gerontology, 2004;1: 1.

37. Janneke Schilp, Hinke M., Kruizenga R.D., Hanneke A.H. Wijnhoven, Eva Leistra, Anja M., Evers R.D., et al: High prevalence of undernutrition in Dutch community-dwelling older Individuals. Nutrition, 2012;28: 1151-1156.
38. Rist G, Miles G, Karimi 1. The presence of malnutrition in community-living older adults receiving home nursing services. Nutrition \& Dietetics, 2012;69 (1): 46-50.

39. Watterson C, Fraser A, Banks M, Isenring E, Miller M, Silvester K, Hoevenaars $R$, et al. Evidence based guidelines for nutritional management of malnutrition in adult patients across the continuum of care. Nutr Diet., 2009;66: 1-34.

40. Visvanathan R, Macintosh C, Callary M, Penhall R, Horowitz M, Chapman I. The nutritional status of 250 older australian recipients of domiciliary care services and its association with outcomes at 12 months. Journal of the American geriatrics Society, 2003;51(7):1007-11.

41. Baweja, S., H. Agarwal, A. Mathur, J.R. Haldiyaa and A. Mathur. Assessment of Nutritional Status and Related Risk Factors in Community Dwelling Elderly in Western Rajasthan. Journal of the Indian Academy of Geriatrics, 2008;5-13.

42. Soini, H., P. Routasalo and H. Lagstrom. Characteristic of the mininutritional assessment in elderly home care patients. European Journal of Clinical Nutrition, 2004;58: $64-70$.

43. Sarah, F. and G. Salah. Age as a determinant of nutritional status: A cross sectional study. Nutritional Journal, 2005;4:28.

44. Georgie Rist, Gail Miles and Leila Karimi. The presence of malnutrition in community-living older adults receiving home nursing services. Nutrition \& Dietetics, 2012;69: 46-50.

45. Winter J, Flanagan D, Mcnaughton S.a. et al. Nutrition Screening of Older People in a Community. General Practice Using the MNA-SF. The Journal of Nutrition, Health \& Aging, 2013;17: 4

46. Cabrera MAS, Mesas AE, Garcia ARL, De Andrade SM. Malnutrition and depression among community-dwelling elderly people. Journal of the American Medical Directors association, 2007;8(9):582-4

47. Kvamme J-M, Grønli O, Florholmen J, Jacobsen BK. Risk of malnutrition is associated with mental health symptoms in community living elderly men and women: the tromsø study. BMC Psychiatry, 2011;11:112.

48. Donini LM, Savina C, Cannella C. Eating habits and appetite control in the elderly: the anorexia of aging. Int Psychogeriatr. 2003;15:73-87.

49. Walker D, Beauchene R. The relationship of loneliness, social isolation, and physical illness to dietary adequacy of independent living elderly. Journal of American Dietetic Association, 1991;91:300-4.

50. Maliheh Aliabadi, Masood Kimiagar, Majid Ghayour-Mobarhan et al Prevalence of malnutrition in free living elderly people in Iran: a crosssectional study. Asia Pac J Clin Nutr,2008;17 (2):285-289

51. Saka B, Kaya O, Ozturk GB, Erten N, Karan MA. Malnutrition in the elderly and its relationship with other geriatric syndromes. Clin Nutr, 2010;29(6):7458.

52. Lee CK, Kong BM, Chan EL, et al. The prevalence and risk factors of proteinenergy malnutrition in three different institutions for elderly Chinese in Hong Kong. Journal of the Hong Kong Geriatrics Society, 2000;10:5-9.

53. Pearson JM, Schlettwein-Gsell D, Brzozowska A, van Staveren WA, Bjornsbo K. Life style characteristics associated with nutritional risk in elderly subjects aged 80-85 years. J Nutr Health Aging, 2001;5:278-83. 